xuất bản $Y$ hoc.

2. Vương Hùng (1997), Kỹ thuật ngoại khoa, Nhà xuất bản $Y$ hoc

3. Thái Nguyến Hưng (2020): Đánh giá kết quả điều tri phâu thuât xuất huyết tiêu hóa cao, Đề tài cơ sở BV K.

4. Nguyê̂n Võ Vĩnh Lộc(2013): Đặc điểm lâm sàng,cận lâm sàng và kết quả sớm điều trị thủng dạ dày do ung thư', Luận văn tốt nghiệp bác sỹ nội trú, Đại học Y Dược TP Hồ Chí Minh.
5. Thái Nguyên Hưng và Bùi Thanh Thiện (2021), "Đánh giá kết quả điều trị phẫu thuật xuất huyết tiêu hóa cao do ung thư hang môn vị da dày.", Tạp chí Y học Việt Nam. 504(2).

6. Thái Nguyên Hựng và Trịnh Vằn Tuấn (2013), "Điêuu trị phẫu thuật chảy máu đường mật do sỏi có sử dụng nội soi đường mật bằng ống soi mềm", Tap chí nghiên cứu $Y$ hoc. 83்(3).

7. Trân Thiện Trung (2014), Ủng thư dạ dày bệnh sinh, chẩn đoán, điêu trị, NXB Y học.

\title{
ĐÁNH GIÁ HIỄU QUẢ CỦA PHƯƠNG PHÁP AN THẦN DO BÊNNH NHÂN TỰ ĐIỀU KHIỂN BẰNG PROPOFOL ĐỂ CHỌC HÚT NOÃN THỤ TINH TRONG ỐNG NGHIỆM
}

\author{
Nguyễn Hoàng Định ${ }^{1}$, Nguyễn Duy Ánh ${ }^{2}$, Nguyễn Đức Lam $^{3}$
}

\section{TÓM TẮT}

Muc tiêu: Đánh giá hiệu quả của phương pháp an thần do bệnh nhân tự kiểm soát bằng propofol (PCS) để chọc hút noãn thụ tinh trong ống nghiệm. Phương pháp: Tiến cứu, thử nghiệm lâm sàng ngẫu nhiên có so sánh, 60 bệnh nhân chọc hút noãn được phân bổ ngẫu nhiên thành 2 nhóm. Nhóm 1 (nhóm PCS, $\mathrm{n}_{1}=$ 30) sử dung phương pháp an thần do bênh nhân tự điều khiển (thuốc Propfol 1\%, mối lần bệnh nhân bấm máy sẽ bơm vào $20 \mathrm{mg}$, không cài thời gian trơ. Nhóm 2 (nhóm GM, $\mathrm{n}_{2}=30$ ) là nhóm gây mê tĩnh mạch thông thường (thuốc Propofol $1 \%$ liều $2 \mathrm{mg} / \mathrm{kg}$ tî̃nh mạch ngắt quãng do người gây mê kiểm soát). Bệnh nhân của 2 nhóm đều được sử dụng $0,05 \mathrm{mg} 50$ mcg fentanyl tiêm tĩnh mạch và gây tê cạnh cố tử cung bằng $100 \mathrm{mg}$ lidocain $1 \%$. Chúng tôi đánh giá mức độ an thân $(\mathrm{OAA} / \mathrm{S})$, tổng liều propofol, thời gian hồi tỉnh và xuất viện, tỉ lệ cử động của bệnh nhân khi làm thủ thuât, mức độ hài lòng của bênh nhân và phẫu thuât viên. Kết quả: Nhóm PCS mức độ an thân trung bình từ 3,87 đên 4,2 điểm trong khi nhóm GM có mức đô an thân từ 1,6 đến 2,1 điểm (do lượng propofol tiêu thu ở nhóm PCS là $52,7 \pm 11,1 \mathrm{mg}$ thấp hơn so với nhóm GM $(151,7 \pm 18,9 \mathrm{mg})$, thời gian hồi tỉnh và thời gian xuất viên của nhóm PCS $(1,7 \pm 0,5$ và $56,6 \pm$ $15,4)$ cũng thấp hơn so với nhóm $\mathrm{GM}(6,9 \pm 1,9$ và $86,5 \pm 25,4)$ với $p<0,05$. Tỉ lệ bênh nhân cử động trong khi làm thủ thuật, mức độ hài lòng của phẫu thuật viên và của bệnh nhận của 2 nhóm không có sự khác biệt. Kết luận: Phương pháp an thần do bệnh nhân tự điều khiển (PCS) bằng Propofol, phối hợp với gây tê cạnh cổ tử cung bằng lidocain trong chọc hút noãn có hiệu quả vô cảm tốt, giúp bênh nhân giảm tình trạng an thần sâu, giảm lượng thuốc mê tiêu thụ,

${ }^{1}$ Bệnh viện $A$ Thái Nguyên

${ }^{2}$ Bềnh viện Phù sản HN

${ }^{3}$ Dai hoc Y Hà Nôi

Chịu trách nhiệm chính: Nguyễn Hoàng Định

Email: Hoangdinhgmhs@gmail.com

Ngày nhân bài: 8.7.2021

Ngày phản biên khoa hoc: 3.9.2021

Ngày duyệt bài: 10.9.2021 giảm thời gian hồi tỉnh và thời gian xuất viện so với nhóm gây mê tĩnh mạch thông thường.

Tư khóa: An thần tự kiểm soát, gây tê Paracervical block, chọc hút noãn, nhu câuu propofol, điểm $O A A / S$ ).

\section{SUMMARY \\ PATIENT CONTROLLED SEDATION BY PROPOFOL FOR OOCYTE RETRIEVAL PROCEDURE}

Objectives: Evaluation of the effectiveness of patient-controlled sedation with propofol (PCS) for in vitro fertilization. Methods: Prospective, randomized, comparative clinical trial, 60 patients with oocyte retrieval were randomly assigned to 2 groups. Group 1 (PCS group, $\mathrm{n} 1=30$ ) used patient-controlled sedation (Propfol 1\% drug, each time the patient presses the machine will inject $20 \mathrm{mg}$, no refractory time set Group 2 (GM group), $\mathrm{n} 2=30$ ) was the usual intravenous anesthesia group (Propofol $1 \%$ dose $2 \mathrm{mg} / \mathrm{kg}$ intravenous intermittent controlled by the anesthesiologist). Patients in both groups received $0.05 \mathrm{mg} 50 \mathrm{mcg}$ fentanyl. intravenous injection and paracervical anesthesia with $100 \mathrm{mg}$ lidocaine $1 \%$.We assessed the degree of sedation (OAA/S), total dose of propofol, time to recovery and discharge, and the patient's movement rate during procedure, patient and surgeon satisfaction. Results: The PCS group had an average sedation level of 3.87 to 4.2 points while the GM group had a sedation level of 1.6 to 2.1 points (due to the amount of propofol consumed in the PCS group was $52.7 \pm 11$ points). $1 \mathrm{mg}$ lower than GM group (151.7 $\pm 18.9 \mathrm{mg})$, recovery time and hospital discharge time of PCS group (1.7 \pm 0.5 and $56.6 \pm 15.4)$ as well. lower than that of the GM group $(6.9 \pm 1.9$ and $86.5 \pm 25.4$ ) with $p<0.05$. The percentage of patients moving during the procedure, the surgeon's satisfaction level and of patients of the 2 groups there was no difference. Conclusion: Patient-controlled sedation (PCS) with Propofol, combined with paracervical anesthesia with lidocaine in oocyte retrieval has good analgesia, helps patients reduce deep sedation, reduce anesthetic consumption, 
reduced recovery time and hospital discharge time compared with the conventional intravenous anaesthesia group.

Keywords: Patient-controlled Paracervical block anesthesia, oocyte retrieval, demand for propofol, OAA/S score.

\section{I. ĐĂT VẤN ĐỀ}

Kỹ thuật thụ tinh trong ống nghiệm gồm 4 quá trình: kích noãn, thu hồi noãn đã chín (chọc hút noãn), tiêm trùng vào noãn và chuyển phôi vào buồng tử cung. Trong đó quá trình thu hồi noãn đã chín gây lo lắng và đau đớn nhất cho bệnh nhân cần sự giúp đỡ của các bác sỹ Gây mê [1], [2].

Quá trình thu hồi noãn trong thời gian không dài, nhưng vẫn phải đảm bảo an thần, giảm đau cho bênh nhân và thuân lợi cho bác sỹ làm thủ thuât. Phương pháp vổ cảm thông thường cho thủ thuật này là gây mê tĩnh mạch bằng propofol. Tuy nhiên, có các nghiên cứu thấy sự xuất hiện và gia tăng nồng độ của thuốc gây mể ở trong dịch nang noãn và nồng độ prolactin trong máu tỉ lệ thuận với thời gian gây mê, vì vây, giảm thiểu lượng thuốc mê sử dụng là yêu cầu được đặt ra [3],[4].

Phương pháp an thần do bênh nhân tự điều khiển bằng propofol đường tînh mạch (PCS patient-controlled sedation) là phương pháp an thần mà người bệnh chủ động bấm nút điều khiển bơm tiêm điện để máy tự động tiêm vào những liều nhỏ thuốc mê propofol sao cho bênh nhân vẫn tỉnh nhưng không lo lắng, khi phối hợp với gây tê vùng để giảm đau thì có thể tiến hành thủ thuật mà không phải gây mê toàn thân. Phương pháp an thân này đã được sử dụng nhiều nơi trên thế giới, ở nước ta cũng đã có mô̂t số nghiên cứu áp dụng trong nhổ răng khôn, nội soi đại tràng, hút thai tuy nhiên trong thủ thuất chọc hút noãn chưa được tác giả nào đề cập đến [5],[6]. Vì vậy, chúng tôi tiến hành nghiển cứu này nhằm mục tiêu: " Đánh giá hiệu quả của phương pháp an thần bằng propofol do bệnh nhân tự điều khiển (PCS) để chọc noãn thụ tinh trong ông nghiệm".

\section{KẾT QUẢ NGHIÊN CỨU} * Đặc điểm chung.

Bảng 1. Đăc điểm chung đôî tương nghiên cứu

\begin{tabular}{|c|c|c|c|}
\hline ĐÁC ĐIËM & Nhóm PCS $\left(n_{1}=30\right)$ & Nhóm GM $\left(n_{2}=30\right)$ & $\mathbf{p}$ \\
\hline Tuối (năm) & $29.1 \pm 3,2$ & $29,8 \pm 2,8$ & $>0,05$ \\
\hline Chiều cao $(\mathrm{cm})$ & $1,54 \pm 0,5$ & $1,54 \pm 0,5$ & $>0,05$ \\
\hline Cân nặng (kg) & $52,3 \pm 2,9$ & $52,9 \pm 2,9$ & $>0,05$ \\
\hline BMI & $22,1 \pm 1,7$ & $22,1 \pm 1,8$ & $>0,05$ \\
\hline Số noãn & $11,7 \pm 3,6$ & $14,3 \pm 3,8$ & $>0,05$ \\
\hline Thời gian chọc noãn (phút) & $9,2 \pm 3,6$ & $11,3 \pm 3,9$ & $>0,05$ \\
\hline
\end{tabular}

II. ĐỐl TƯỢNG VÀ PHƯƠNG PHÁP NGHIÊN CỨU

2.1. Đối tượng nghiên cứu: là các bênh nhân từ 18 - 50 tuổi, ASA I,II. Có chỉ định chọc hút noãn để làm thụ tinh trong ống nghiệm, thời gian từ tháng 2/2021 đến tháng 8/2021.

\subsection{Phương pháp nghiên cứu}

*Thiết kế nghiên cứu: Nghiên cứu tiến cứu, lâm sàng, ngâu nhiên có đối chứng.

*Cõ̃ mẫu: 60 bệnh nhân chia làm 2 nhóm bằng bốc thăm ngấu nhiên.

Nhóm 1 (Nhóm PCS) $n_{1}=30$ bệnh nhân: Sử dụng phương pháp an thần do bệnh nhân tự điều khiển.

Nhóm 2 (Nhóm GM) $n_{2}=30$ bênh nhân: Sử dụng phương pháp gây mê tĩnh mach.

*Phương pháp tiến hành: Bệnh nhân được tiền mê: tiêm 50 mcg fentanyl tĩnh mạch chậm. Nhóm 1 bênh nhân được gây tê cổ tử cung 2 bên với Lidocain $1 \%$ liều $100 \mathrm{mg}$, sau đó bệnh nhân tự bấm máy bơm tiêm điện, liều mỗi lần tiêm là $20 \mathrm{mg}$ Propofol $1 \%$, bệnh nhân tự bấm những liều tiếp theo nếu cảm thấy lo lắng. Nhóm 2: bệnh nhân được gây mê bằng tiêm $\mathrm{TM}$ propofol $1 \%$ liều $2 \mathrm{mg} / \mathrm{kg}$ trong 30 giây, duy trì mê với propofol $0,5 \mathrm{mg} / \mathrm{kg}$ tiêm ngắt quãng bổ sung sau mỗi 4 - 5 phút khi điểm OAA/S $\geq 3$.

* Các tiêu chuẩn đánh giá: Các đặc điểm liên quan đến bệnh nhân, đặc điểm quá trình gây mê và thủ thuật. Mức độ an thần của bệnh nhân, tổng liều propofol đã dùng, thời gian hồi tỉnh và xuất viên, mức độ cử động cản trở trong khi làm thủ thuật.

*Các thời điểm theo dõi nghiên cứu: $T_{0}$ : Sau khi tiền mê 1 phút tiến hành vệ sinh âm đạo. $T_{1}$ : Thời điểm 1 phút sau dùng liều an thần hoăc khởi mê đầu tiên. $T_{2}$ : Thời điểm 2 phút sau khi bắt đầu thủ thuật. T4: Thời điểm 4 phút sau khi bắt đầu thủ thuật. T6: Thời điểm 6 phút sau khi bắt đầu thủ thuất. T8: Thời điểm 8 phút sau khi bắt đầu thủ thuất. Tкт: Thời điểm kết thúc thủ thuật. THт: Thời điểm khi bệnh nhân tỉnh táo hoàn toàn. Txv: Thời điểm khi bệnh nhân xuất viện. 
Nhận xét: Các chỉ số tuổi, chiều cao, cân nặng, BMI, số noãn và thời gian chọc giữa 2 nhóm không có sự khác biệt có ý nghĩa thống kê.

* Hiệu quả vô cảm:

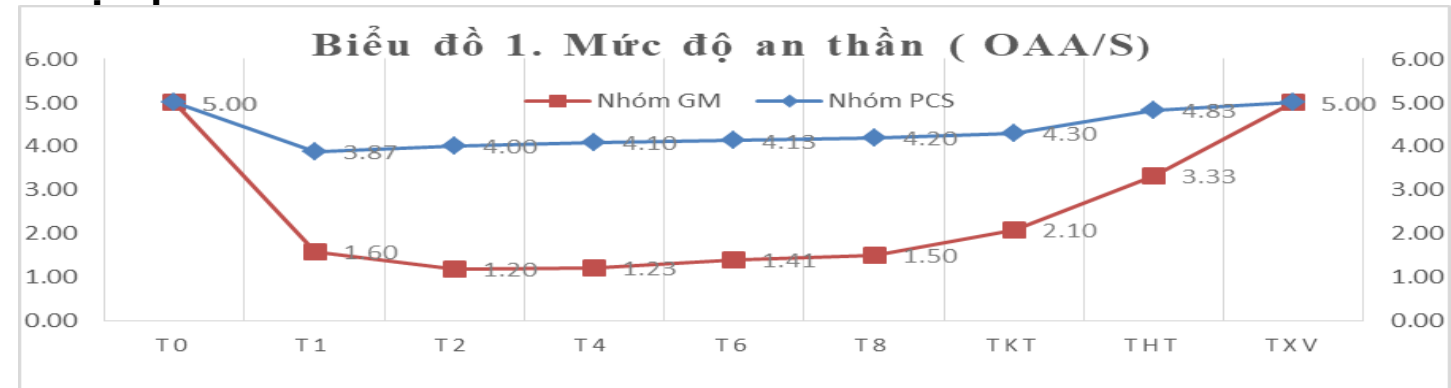

Nhận xét: Độ an thần có sự khác biệt có ý nghĩa thống kê giữa nhóm nghiên cứu PCS và nhóm GM ở các thời điểm $T_{1}, T_{2}, T_{4}, T_{6}, T_{8}, T_{K T}, T_{H T}(p<0,05)$.

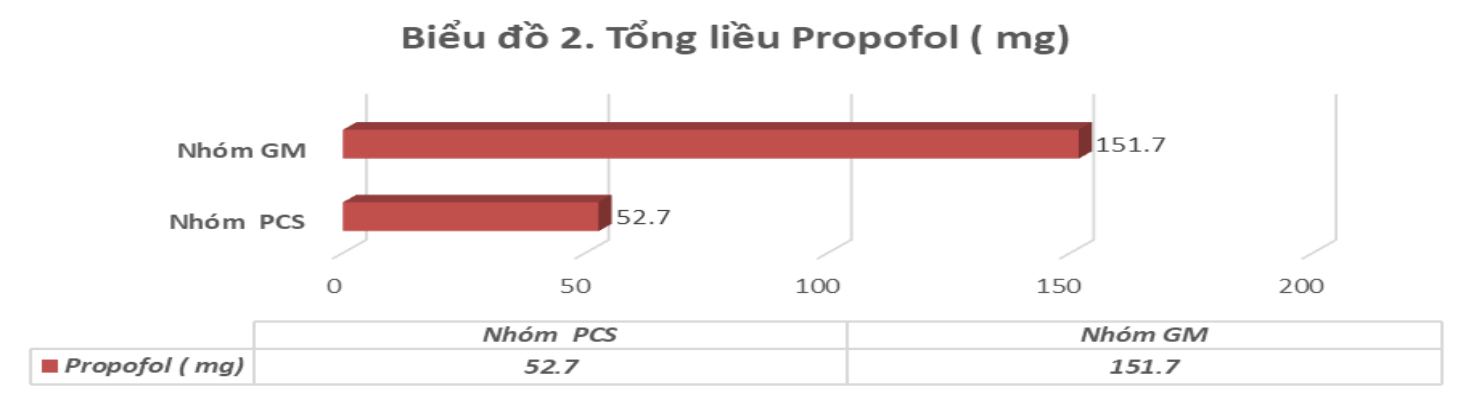

Nhận xét: Tổng lượng Propofol tiêu thụ của hai nhóm nghiên cứu khác biệt có ý nghĩa thống kê với $p<0,01$. Tổng lượng Propofol tiêu thụ cao nhất là $200 \mathrm{mg}$ và thấp nhất là $40 \mathrm{mg}$.

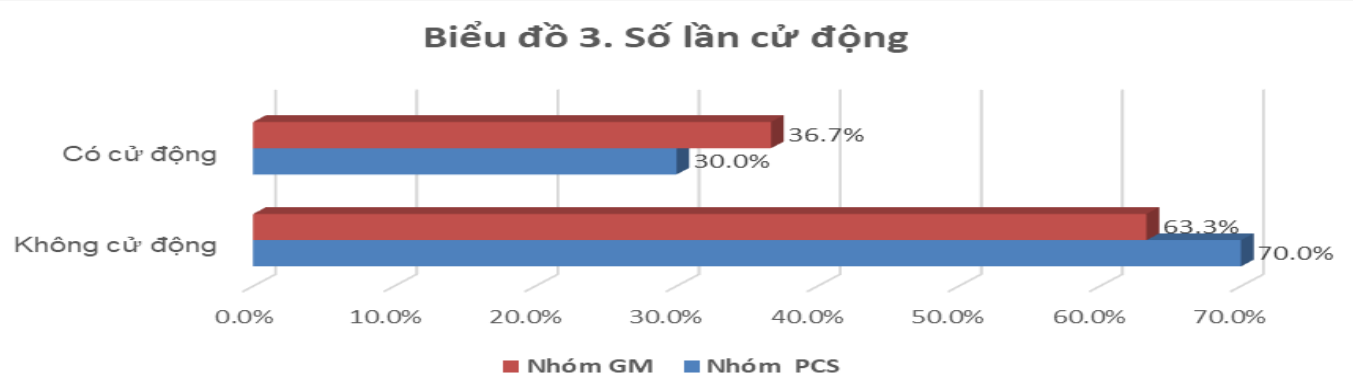

Nhận xét: Tỷ lệ bệnh nhân cử động của hai nhóm nghiên cứu khác biệt không có ý nghĩa thống kê với $\mathrm{P}>0,05$.

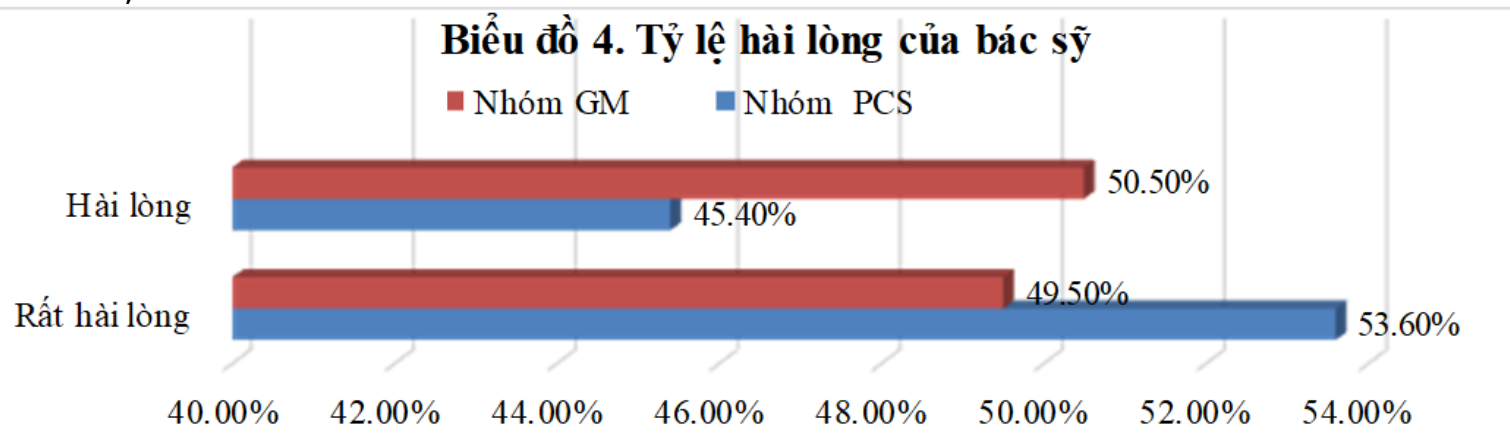

Nhận xét: Tỷ lệ hài lòng của phẫu thuật viên ở cả hai nhóm nghiên cứu không sự có sự khác biệt ý nghĩa thống kê với p> 0,05. 


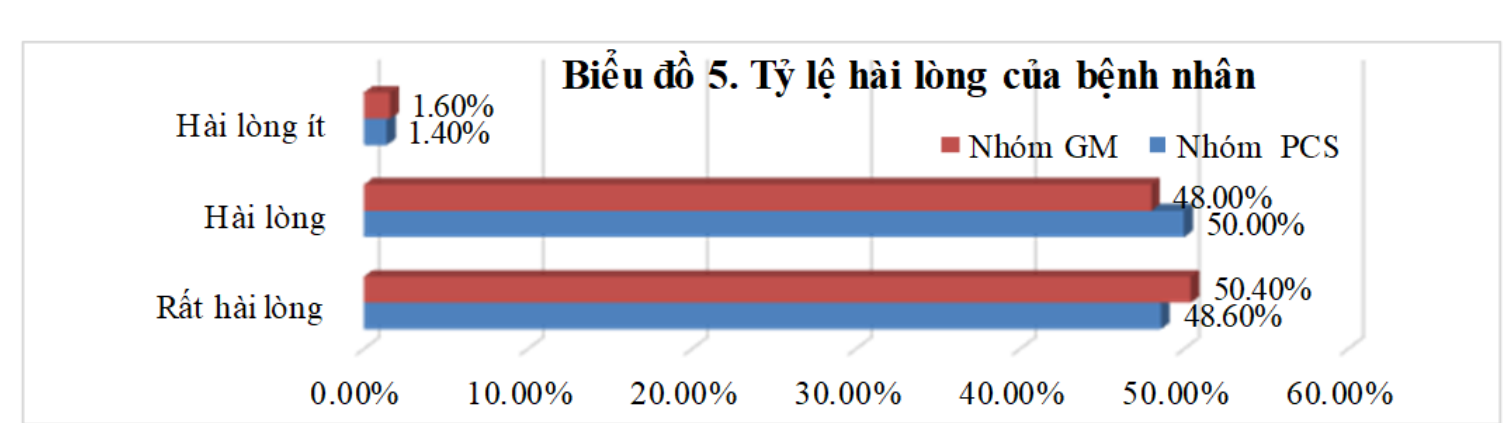

Nhận xét: Tỷ lệ hài lòng của bệnh nhân ở cả hai nhóm nghiên cứu không sự có sự khác biệt ý nghĩa thống kê vớ $P>0,05$.

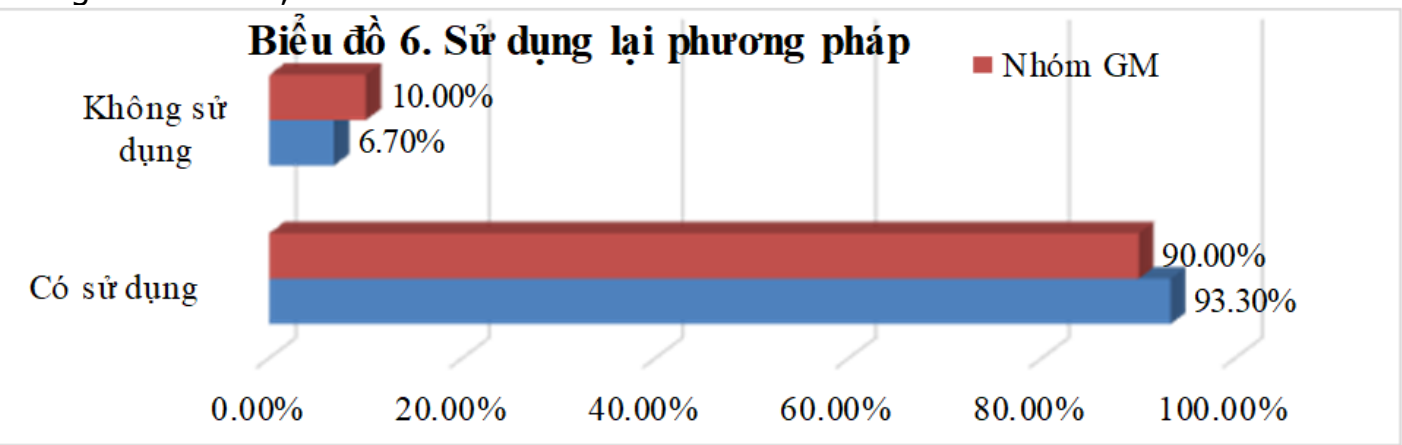

Nhận xét: Phần lớn bệnh nhân của hai nhóm nghiên cứu đều muốn sử dụng lại phương pháp ở lần sau, không có sự khác biệt ý nghĩa thông kê với p > 0,05.

\section{BÀN LUÂNN}

* Đăc đaiểm chung. Trong nghiên cứu của chúng tổi, các chỉ số tuổi, chiều cao, cân nặng, BMI giữa 2 nhóm không có sự khác biệt. Số noãn nhóm PCS là $11,7 \pm 3,6$ noãn với thời gian chọc noãn trung bình 9,2 $\pm 3,6$ phút tương tự với nhóm GM là $14,3 \pm 3,8$ noãn với thời gian chọc noãn trung bình $11,3 \pm 3,9$. Kết quả này cũng tương tự nghiên cứu của Trịnh Xuân Trường [8], phù hợp với đặc điểm phụ nữ Việt Nam.

* Hiệu quá vô cảm: Độ an thần (theo $\mathrm{OAA} / \mathrm{S}$ ): Theo biểu đồ 1 . Độ an thần của nhóm PCS ở các thời điểm $T_{1}, T_{2}, T_{4}, T_{6}, T_{8}, T_{K T}, T_{H T}$ chỉ dao động từ 3,87 đến 4,2 điểm là mức an thần tỉnh trong thời gian tiến hành thủ thuật, kết quả của chúng tôi phù hợp với kết quả của Nguyễn Quang Bình. Mức an thần ở nhóm GM ở các thời điểm $T_{1}, T_{2}, T_{4}, T_{6}, T_{8}, T_{K T}$, giảm so với thời điểm $T_{0}$, điểm an thần từ 1,6 đến 2,1 điểm thấp hơn nhóm PCS sự khác biệt có ý nghĩa thống kê ( $p$ < $0,05)$ kết quả tương đồng với nghiên cứu của Osborne [5] và cộng sự. Sự khác biệt này là do tổng lượng Propofol của nhóm PCS thấp hơn nhóm GM $(52,7 \pm 11,1$ so với $151,7 \pm 18,9)$.

Tổng lượng thuốc mê propofol tiêu thụ: Theo biểu đồ 2. Lượng Propofol tiêu thụ của nhóm GM trong nghiên cứu của chúng tôi ià $151,7 \mathrm{mg}$, nghiên cứu của Trịnh Xuân Trường [8] là 206,32 $\pm 22,43 \mathrm{mg}$. Trong khi đó nhóm PCS với nghiên cứu của chúng tôi chỉ sử dụng $52,7 \mathrm{mg}$. Như vậy, phương pháp an thần do bệnh nhân tự điều khiển (PCS) giúp làm giảm đáng kể lượng tiêu thụ thuốc mê. Dấn tới giảm thời gian hồi tỉnh và thời gian nằm viện của PCS so với nhóm GM lần lượt là $(1,7 \pm 0,5$ và $56,6 \pm 15,4)$ so với $(6,9 \pm$ $1,9$ và $86,5 \pm 25,4)$.

Tỉ lệ bệnh nhân cử động: Theo biểu 3. của hai nhóm nghiên cứu là $30 \%$ và $36,7 \%$ khác biệt không có ý nghĩa thống kê với $P>0,05$. Kết quả của chúng tôi cao hơn của Nguyễn Quang Bình [6], có thể do trong nghiên cứu của chúng tôi bệnh nhân ngoài có cảm giác tức bụng khi bị đầm kim vào buồng trứng hoăc khi cố định buồng trứng bằng cách ép vào thành bụng. Đặc biệt, ở nhóm GM có mức an thần sâu hơn nhóm PCS nhưng số lần cử động cũng không ít hơn khi làm thủ thuật đây cũng là một yếu tố quan trọng vì khi tiến hành thủ thuật bệnh nhân nằm im hợp tác thì phẫu thuật viên mới thuận lợi tiến hành thủ thuật được.

Tỷ lệ hài lòng của bác sỹ: Kết quả ở biểu đồ 4. Tỉ lệ bác sỹ hài lòng khi tiến hành thủ thuật chọc noãn ở 2 nhóm lần lượt là nhóm PCS 99\%, nhóm GM $98 \%$ (Hài lòng và Rất hài lòng) sự khác biệt không có ý nghĩa thống kê giữa 2 nhóm. Điều này cho thấy cả hai phương pháp 
đều đảm bảo vô cảm tốt, thuận lợi cho thủ thuật. Sự hài lòng của thủ thuật viên gián tiếp đánh giá hiệu quả của việc sử dụng an thần.

Kết quả nghiên cứu của chúng tôi cũng phù hợp với kết quả nghiên cứu của Hoàng Ngọc Vinh[7] và của Nguyễn Quang Bình [6]. Propofol có tác dụng an thần, tăng tác dụng của thuốc giảm đau gây tê và làm mềm cơ nên thuận lợi cho thủ thuật chọc noãn.

Sự hài lòng của bệnh nhân và sử dụng lại cùng phương pháp: Kết quả ở biểu 5 . và biểu đồ 6. mức độ hài lòng của bệnh nhân ở 2 nhóm khác nhau không có ý nghĩa thống kê $(98,6 \%$ ở nhóm PCS và $98,4 \%$ ở nhóm $G M$ với $p>0,05$ ). Như vậy tác dụng an thần của propofol giúp cho bệnh nhân thoải mái, hợp tác tốt hơn trong khi làm thủ thuật, sự hài lòng của bệnh nhân là yếu tố khách quan đánh giá hiệu quả của phương pháp vô cảm. Kết quả của chúng tôi cũng phù hợp với Nguyễn Quang Bình [6]. Tỷ lệ bệnh nhân mong muốn được áp dụng cùng phương pháp vô cảm nếu phải chọc noãn lần sau ở 2 nhóm khác nhau không có ý nghĩa thông kê với $\mathrm{p}>0,05$ (95,8\% ở nhóm PCS và $97,6 \%$ ở nhóm $\mathrm{GM})$. Kết quả này của chúng tôi cũng phù hợp với các nghiên cứu trong nước và quốc tế. Điểu này cho thây phương pháp an thần do bệnh nhân tự điều khiển có hiệu quả tương đương với gây mề tĩnh mạch để chọc noãn.

\section{KẾT LUẬN}

Phương pháp an thần do bênh nhân tự điều khiển (PCS) bằng Propofol, phối hợp với gây tê cạnh cổ tử cung bằng lidocain trong chọc hút noãn có hiệu quả vô cảm tốt, giúp bệnh nhân giảm tình trạng an thần sâu, giảm lượng thuốc mê tiêu thụ, giảm thời gian hồi tỉnh và thời gian xuất viện so với nhóm gây mê tĩnh mạch thông thường.

\section{TÀI LIẸU THAM KHẢO}

1. Jain D, Kohli A, Gupta L, Bhadoria P, Anand R. Anaesthesia for In Vitro Fertilisation. Indian J Anaesth. 2009;53(4):408-413.

2. Kwan I, Wang R, Pearce E, Bhattacharya S. Pain relief for women undergoing oocyte retrieval for assisted reproduction. Cochrane Database Syst Rev. 2018;5:CD004829.

3. Hayes MF, Sacco AG, Savoy-Moore RT, Magyar DM, Endler GC, Moghissi KS. Effect of general anesthesia on fertilization and cleavage of human oocytes in vitro. Fertil Steril. 1987; 48(6): 975-981.

4. Botta G, D'Angelo A, D'Ari G, Merlino G, Chapman M, Grudzinskas G. Epidural anesthesia in an in vitro fertilization and embryo transfer program. J Assist Reprod Genet. 1995; 12(3):187-190.

5. Osborne GA, Rudkin GE, Jarvis DA, Young IG, Barlow J, Leppard PI. Intra-operative patientcontrolled sedation and patient attitude to control. A crossover comparison of patient preference for patient-controlled propofol and propofol by continuous infusion. Anaesthesia.

6. Nguyê̂n Quang Bình. Nghiên cứu phương pháp an thân bă̆ng propofol do bệnh nhân țư điều khiển trong phẫu thuật răng - LUẬN ÁN TIẾN SĨ. Published online 2012.

7 Hoàng Ngọc Vinh. Nghiên cứu hiệu quả an thần bằng propofol do bệnh nhân tự điều khiển trong hút thai. Luận văn Tiến sỹ y học Đại học Y Hà Nội. Published online 2016.

8. Trịnh Xuân Trường (2015), Chương HV, Thạch NN, Kiên NT, Khoa NV. Gây mê Propofol chọc hút noắn và Fentanyl trong chọc hút noãn.

\section{ĐĂC ĐIỂM TỔN THƯƠNG TRÊN CẮT LỚP VI TÍNH Ở BÊNH NHÂN GÃY MŨI SÀNG Ổ MẮT TẠI BỆNH VIỆN HŨ̃U NGHI VIỆT ĐỨC}

\section{TÓM TẮT}

Mục tiêu: Nghiên cứu này được thực hiện nhằm mô tả các đặc điểm tổn thương trền $\mathrm{CLVT}$ của nhóm bệnh nhân được điều trị tại Khoa Phẫu thuật Hàm mặt-Tạo hình- Thẩm mỹ, Bệnh viện Hữu nghị Việt

\footnotetext{
IViện Đào Tạo Răng Hàm Mặt, Trường Đại học Y Hà Nội Bệnh viện Hữu nghi Việt Đức

Chịu trách nhiệm chính: Phan Văn Anh

Email: superbio1995@gmail.com

Ngày nhận bài: 5.7.2021

Ngày phản biện khoa học: 30.8.2021

Ngày duyệt bài: 8.9.2021
}

\section{Phan Văn Anh ${ }^{1}$, Nguyễn Hồng Hà ${ }^{2}$, Lê Văn $\mathrm{Nam}^{2}$}

Đức. Qua đó, góp phân hỗ trơ các bác sĩ trong việc chẩn đoán và lên kế hoạch điều trị cho những bệnh nhân gãy MSOM. Đối tượng và phương pháp: Nghiên cứu mô tả chùm ca bệnh dựa trên phim CLVT ở 43 bệnh nhân gãy MSOM được điều trị từ thàng 01/2020 đến tháng 04/2021 tại Khoa Hàm mặt- Tạo hình- Thẩm mỹ, Bệnh viện Hữu nghị Việt Đức. Dùng phần mềm SPSS để phân tích số liệu thống kê. Kết quả: Trong số 43 bệnh nhân, có 37 bệnh nhân (86\%) có tổn thương khớp trán - xương hàm trên, $100 \%$ có tổn thương khuyết lệ - bờ dưới ổ mắt, 33 bệnh nhân có tổn thương thành trong ổ mắt $(76,7 \%)$, tổn thương xương chính mũi thây ở 30 bệnh nhân $(69,8 \%), 34$ bệnh nhân có tổn thương vách ngăn $(79,1 \%), 42$ bệnh nhân có tụ dịch xoang sàng $(97,7 \%)$ và 14 bệnh 